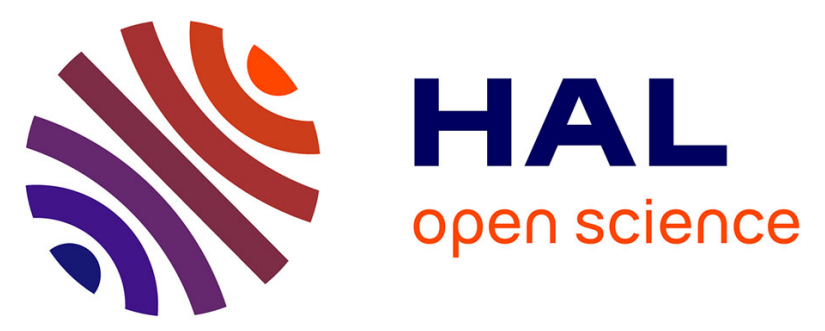

\title{
Dynamics of a "low-enrichment high-retention" upwelling center over the southern Senegal shelf
}

Siny Ndoye, Xavier Capet, Philippe Estrade, Bamol Sow, Éric Machu, Timothée Brochier, Julian Döring, Patrice Brehmer

\section{To cite this version:}

Siny Ndoye, Xavier Capet, Philippe Estrade, Bamol Sow, Éric Machu, et al.. Dynamics of a "lowenrichment high-retention" upwelling center over the southern Senegal shelf. Geophysical Research Letters, 2017, 44 (10), pp.5034 - 5043. 10.1002/2017GL072789 . hal-01630513

\section{HAL Id: hal-01630513 https://hal.science/hal-01630513}

Submitted on 18 May 2020

HAL is a multi-disciplinary open access archive for the deposit and dissemination of scientific research documents, whether they are published or not. The documents may come from teaching and research institutions in France or abroad, or from public or private research centers.
L'archive ouverte pluridisciplinaire HAL, est destinée au dépôt et à la diffusion de documents scientifiques de niveau recherche, publiés ou non, émanant des établissements d'enseignement et de recherche français ou étrangers, des laboratoires publics ou privés. 


\section{Geophysical Research Letters}

\author{
RESEARCH LETTER \\ 10.1002/2017GL072789 \\ Key Points: \\ - Upwelling dynamics over the \\ southern Senegal shelf strongly differs \\ from 2-D Ekman theory \\ - Overall upwelling intensity is only \\ $15-40 \%$ of the Ekman transport \\ - High retention over the southern \\ Senegal shelf favors small pelagic fish \\ reproduction
}

Supporting Information:

- Supporting Information S1

Correspondence to:

S. Ndoye,

ndoyesiny@yahoo.fr

\section{Citation:}

Ndoye, S., X. Capet, P. Estrade, B. Sow, E. Machu, T. Brochier, J. Döring, and P. Brehmer (2017), Dynamics of a "low-enrichment high-retention" upwelling center over the southern Senegal shelf, Geophys. Res. Lett., 44, 5034-5043, doi:10.1002/2017GL072789.

Received 30 JAN 2017 Accepted 26 APR 2017 Accepted article online 27 APR 2017 Published online 29 MAY 2017

\section{Dynamics of a "low-enrichment high-retention" upwelling center over the southern Senegal shelf}

\author{
Siny Ndoye ${ }^{1,2}$, Xavier Capet ${ }^{2}$ D ${ }^{\text {Philippe Estrade }}{ }^{1}$, Bamol Sow $^{3}$, Eric Machu ${ }^{1,4}$, Timothée Brochier ${ }^{5}$, \\ Julian Döring ${ }^{6} \mathbb{D}$, and Patrice Brehmer $7,8 \mathbb{D}$ \\ ${ }^{1}$ LPAO-SF, University of Dakar, Dakar, Senegal, ${ }^{2}$ LOCEAN, CNRS-IRD-UPMC-MNHN, University Paris Sorbonne, Paris, \\ France, ${ }^{3}$ LOSEC, Ziguinchor University, Ziguinchor, Senegal, ${ }^{4}$ Universite de Brest, CNRS, IRD, Ifremer, Laboratoire \\ d'Océanographie Physique et Spatiale (LOPS), IUEM, Brest, France, ${ }^{5}$ UMMISCO, IRD, Bondy, France, ${ }^{6}$ Leibniz Center for \\ Tropical Marine Ecology (ZMT), Bremen, Germany, ${ }^{7}$ LEMAR, CNRS-UBO-IRD-Ifremer, Campus UCAD-IRD de Hann, Dakar, \\ Senegal, ${ }^{8}$ Centre de Recherche Ocographique Dakar-Thiaroye, ISRA, Dakar, Senegal
}

Abstract Senegal is the southern tip of the Canary upwelling system. Its coastal ocean hosts an upwelling center which shapes sea surface temperatures between latitudes $12^{\circ}$ and $15^{\circ} \mathrm{N}$. Near this latter latitude, the Cape Verde headland and a sudden change in shelf cross-shore profile are major sources of heterogeneity in the southern Senegal upwelling sector (SSUS). SSUS dynamics is investigated by means of Regional Ocean Modeling System simulations. Configuration realism and resolution ( $\Delta x \approx 2 \mathrm{~km}$ ) are sufficient to reproduce the SSUS frontal system. Our main focus is on the 3-D upwelling circulation which turns out to be profoundly different from 2-D theory: cold water injection onto the shelf and upwelling are strongly concentrated within a few tens of kilometers south of Cape Verde and largely arise from flow divergence in the alongshore direction; a significant fraction of the upwelled waters are retained nearshore over long distances while travelling southward under the influence of northerly winds. Another source of complexity, regional-scale alongshore pressure gradients, also contributes to the overall retention of upwelled waters over the shelf. Varying the degree of realism of atmospheric and oceanic forcings does not appreciably change these conclusions. This study sheds light on the dynamics and circulation underlying the recurrent sea surface temperature pattern observed during the upwelling season and offers new perspectives on the connections between the SSUS physical environment and its ecosystems. It also casts doubt on the validity of upwelling intensity estimations based on simple Ekman upwelling indices at such local scales.

\section{Introduction}

Coastal upwelling rarely takes place in its idealized 2-D alongshore invariant form [Ekman, 1905]. Underwater features and coastline irregularities such as capes, often aided by fine-scale wind features, produce heterogeneities in the upwelling circulation [Barth et al., 2005; Ramp et al., 2005]. Focal areas of intensified upwelling, the so-called upwelling centers, are generally found in association with capes [Brink et al., 1981; Jones et al., 1983]. Each center is associated with unique circulation and dynamics depending on the exact bathymetry and coastline shapes, local wind regime (modulated by nearby orography), regional circulation, etc. The fate of upwelled waters is also strongly dependent on those factors, but upwelling centers are generally associated with filaments that swiftly transport upwelled waters offshore, hence limited nearshore retention of these waters. In sectors dominated by this type of dynamics, upwelling relaxation periods are believed to be essential to the survival and reproduction of many marine species [Yokomizo et al., 2010; Bakun, 1996]. In contrast, upwelling shadows [Graham and Largier, 1997; Roughan et al., 2005] offer environments sheltered from coastal upwelling where reduced offshore drift is exploited by ecosystems. Enrichment by nearby upwelling waters is indirect and intermittent in these sectors [Zhang et al., 2015].

In this study we present numerical evidence for the existence of a variant of nearshore upwelling dynamics in which the surface layer benefits from both direct enrichment by subsurface waters (albeit at a lower rate than Ekman theory predicts) and reduced offshore export of these upwelling waters. This upwelling dynamics is found in the southern Senegal upwelling sector (SSUS, Figure 1a) delimited by the Cape Verde Peninsula and the latitude $12^{\circ} \mathrm{N}$, at the southern tip of the Canary current system (Note that the coastal waters between $13^{\circ} 35^{\prime} 35^{\prime \prime} \mathrm{N}$ and $13^{\circ} 03^{\prime} 27^{\prime \prime} \mathrm{N}$ are those of Gambia). The southern Senegal shelf hosts an upwelling center that
○2017. American Geophysical Union. All Rights Reserved. 

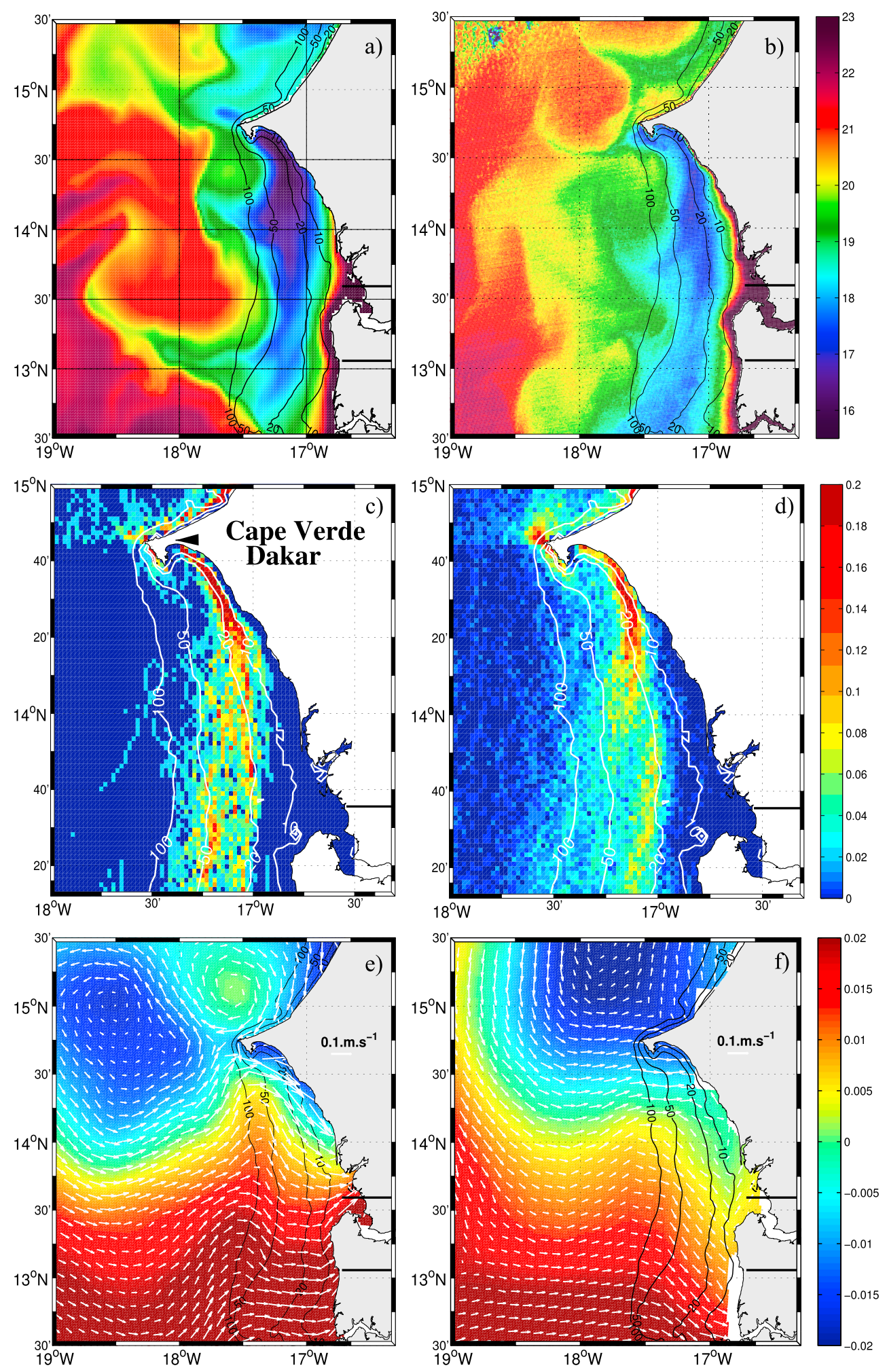

Figure 1. Examples of instantaneous SST $\left({ }^{\circ} \mathrm{C}\right.$ ) fields from (a) $S^{\text {hfw }}$ and (b) L2 MODIS for the core of the SSUS upwelling period (February-April). February-April climatological probability density function for the distribution of zonal SST minima computed in $2 \mathrm{~km}$ latitude bands (longitude binning also uses a $2 \mathrm{~km}$ mesh size) for (c) $\mathrm{S}^{\text {hfw }}$ and (d) L2 MODIS (see details in Ndoye et al. [2014]); note the nonlinear color scales for these two panels. February-April mean climatological sea level from (e) $S^{\text {hfw }}$ and (f) observations combining the 2013 CNES-CLS mean dynamic topography with DUACS monthly sea level anomalies. Isobaths 10,20,50, and $100 \mathrm{~m}$ are also shown. Locations of the Senegal/Gambia borders are shown on land with thick black lines. 
is active during boreal winter and spring (November through May) when the Intertropical Convergence Zone is located in the Southern Hemisphere. The Senegal coastal ocean geomorphology is characterized by a major coastline and bathymetric irregularity near Cape Verde (CV; see Figure 1a). About CV the shape of the continental shelf changes from moderately narrow in the north to broad and shallow in the south (Figure 1). A recurrent sea surface temperature (SST) state in the SSUS is shown in Figure $1 \mathrm{~b}$ (next to a resembling model state, Figure 1a). A tongue of cold upwelled water seems to emanate from south of CV. It extends southward over hundred kilometers or more, roughly parallel to the shoreline, and is generally well confined on the shelf. Note the elongated strip of warmer waters present inshore of the tongue.

SSUS upwelling circulation must differ from the one found for the classical 2-D vertical (2DV) upwelling or in other upwelling centers [Rosenfeld et al., 1994], but very few dynamical studies have investigated this sector. In fact, a SSUS surface circulation scheme has been proposed in the 1970s [Rebert and Privé, 1974] based on 10 days of rotor current meter measurements made in March 1974 and never revisited until very recently. Based on 2DV theory [Estrade et al., 2008], the place where inshore warm waters are found has traditionally been interpreted as a retention area isolated from upwelling influence [Demarcq and Faure, 2000]. This area is a major fishing ground for artisanal fishermen with fishing activities so intense that it frequently precludes research vessel navigation and operation.

Analyses of state-of-the-art 3-D numerical simulations presented below confirm that the SSUS wind-driven circulation is peculiar in many ways. In the model, it is characterized by a strongly reduced upwelling compared to Ekman theory predictions and strong tendency to nearshore retention of upwelling waters which we explain dynamically. In particular, the current view on the warm inshore strip needs to be qualified and revisited: in the model, this strip is composed of waters recently upwelled in the northern SSUS that are progressively warmed as they drift southward in shallow waters. The presence of this warm inshore strip thus exemplifies the long retention tendency of the sector. Circumstantial observational evidence suggests that small pelagic fish take advantage of this system's property.

The study is organized as follows. The model simulations are briefly presented in section 2 . They are subsequently evaluated against observations and analyzed in section 3, using Eulerian and Lagrangian techniques. Conclusions are offered in the final section, including on the SSUS ecosystem functioning and its management.

\section{Materials and Methods}

To investigate the SSUS dynamics and circulation, we carried out several Regional Ocean Modelling System (ROMS) [Shchepetkin and McWilliams, 2005, 2009] simulations for the Canary Current System with a grid nest [Debreu and Blayo, 2008] focusing on the Senegal coastal ocean. Model horizontal resolution offshore of Senegal was $\Delta x \approx 2 \mathrm{~km}$, which is sufficient to resolve the fine-scale dynamical features we are interested in. We use KPP for the vertical turbulence closure [Large et al., 1994]. The model was forced by realistic surface and climatological open boundary conditions from SODA [Carton and Giese, 2008]. Our baseline solution called $S^{\text {hfw }}$ used climatological surface heat/freshwater fluxes with daily winds for the period 1999-2008, i.e., the solution was subjected to forced synoptic and interannual variability. Surface heat/freshwater forcings combine two products (International Comprehensive Ocean Atmosphere Data Set [Worley et al., 2005] and Tropflux [Praveen Kumar et al., 2013]) and a restoring as advocated in Barnier et al. [1995]. For the latter the restoring is toward the observed SST described in Ndoye et al. [2014]. Daily wind forcing combines the monthly climatology of Risien and Chelton [2008] with daily wind anomalies from Bentamy and Fillon [2012].

An additional simulation was computed, with a lower degree of forcing realism ( $S^{\mathrm{clm}}$; climatological wind forcing). This allows us to test the robustness of our conclusions (see Text S2 in the supporting information). Additional details on the model settings, configuration, and sensitivities are provided in the supporting information Text S1.

\section{Results}

\subsection{Model Evaluation}

Model evaluation is limited given the scarcity of in situ data in the SSUS. Model skills are nonetheless confirmed by its ability to qualitatively reproduce key-observed fine-scale $(20-100 \mathrm{~km})$ SST features. These features include the following: (1) the upwelling cold tongue whose mean position (see Figures 1c and 1d) and seasonal across-shore migration amplitude $(\approx 30-40 \mathrm{~km}$ with the most offshore position attained at the 
peak of the upwelling season) are close to the observations [Ndoye et al., 2014]); (2) the occurrence of an anticyclonic mesoscale eddy in the vicinity of $\mathrm{CV}$ as in Figures $1 \mathrm{a}$ and $1 \mathrm{~b}$; and (3) recurrent upwelling filaments (exporting upwelled waters to the open ocean) just north of Cape Verde and about $14^{\circ} \mathrm{N}$ (Figures $1 \mathrm{a}$ and $1 \mathrm{~b}$ ). Note though that shelf surface waters are, on average, $\sim 1^{\circ} \mathrm{C}$ too warm in the model (supporting information Text S2). Because a bias of similar amplitude also seems to affect bottom waters over the outer and midshelf (by comparing the simulation with observations from the UPSEN2/ECOAO experiments) [see Capet et al. [2017, Figure 5], we suspect that the model deficiency arises from a lack of offshore isopycnal tilt resulting in the $15^{\circ} \mathrm{C}$ isotherm being $\sim 20 \mathrm{~m}$ too deep at the shelf break. This type of bias is common in upwelling simulations [Capet et al., 2004].

Seasonal mean sea level compares favorably with observations at regional scale, despite some differences in standing mesoscale patterns (Figures 1e and 1f). We are hesitant on the interpretation of these differences given the well-known limitations of mean dynamic topography estimates at such scales [Rio et al., 2011]. Most importantly, a southward pressure gradient is present in the southern domain in both the model and the Archiving, Validation, and Interpretation of Satellite Oceanographic (AVISO) data. This pressure gradient gives rise to a regional-scale onshore geostrophic flow whose implications for the SSUS dynamics are further described in section 3.3 .

Overall qualitative agreement between observed and modelled thermohaline structures is deemed good enough to justify in-depth analysis of the model dynamics. Note that we find only modest sensitivity to the forcing realism. Adding realistic tides does not appreciably change the subinertial circulation, i.e., tidal rectifcation effects are small (not shown). Removing the wind high frequency (i.e., using climatological winds; $\mathrm{c}^{\mathrm{clm}}$ ) has some impact on the details of the circulation in the vicinity of Cape Verde and locally reduces upwelling by half in places (see below). On the other hand, it does not affect our qualitative results and conclusions as we will justify.

\subsection{Upwelling Disruption by SSUS Geomorphology}

For a 2DV coastal upwelling there is an exact compensation between cross-shore supply and export at any location. This compensation breaks down in the SSUS, and we now investigate the fate of the upwelling waters and in particular how it differs from 2DV theory.

The upwelling tongue pattern strongly suggests that upwelling predominantly occurs in the northern part of the domain where the coldest SSTs are found. We confirm this by showing divergence of the mixed layer horizontal flow (Figure 2). Divergence is essentially confined north of $14^{\circ} 30^{\prime} \mathrm{N}$ over the part of the shelf where the mean surface flow is directed onshore, i.e., opposite to Ekman transport. Further south, divergence is also found in the vicinity of the shelf break but with much smaller values. The decomposition into meridional and zonal components reveals the unusual importance of the divergence component in the meridional (approximately alongshore) direction $\partial_{y} v$ (Figure 2b). It is known that alongshore bathymetric variability can drive upwelling onto a shelf that widens in the downwind direction [Gan et al., 2009]. This is because a wider shelf implies more alongshore transport, and thus, some mass flux onto the shelf is needed to accommodate the change in alongshore transport [Pringle, 2002]. How the circulation is affected by the shelf widening depends on whether the upstream flow can be adjusted through coastal-trapped wave propagation or not. In the upwelling case, some distant adjustment is a priori possible because the direction of coastal wave propagation is against the wind-driven flow. In practice though the SSUS geomorphology and flow regime make such adjustment unlikely (due to scattering, reflection, and dissipation of coastal waves), hence the systematic deflection and separation of the upwelling jet north of $\mathrm{CV}$ (see Figures $1 \mathrm{a}$ and $1 \mathrm{~b}$ for a particular example). Alongshore flow acceleration is thus necessarily localized in the northern SSUS (see the tight correspondence between flow divergence and widening of the isobaths in Figure 2, including inshore of the $20 \mathrm{~m}$ isobath just south of $14^{\circ} 30^{\prime} \mathrm{N}$ ). We interpret the tendency of the SSUS dynamics to produce a mesoscale anticyclonic feature in the vicinity of $\mathrm{CV}$ as a consequence of the local bathymetric constraint on the flow. In the northern SSUS this anticyclone induces onshore geostrophic flow that helps accommodate the alongshore flow divergence over the shelf. This pattern is most pronounced and permanent in the simulation with climatological winds (not shown); i.e., wind synoptic fluctuations are detrimental to the establishment of the quasi-standing mesoscale anticyclone.

The cape and bathymetric irregularities also disrupt the subsurface supply of upwelling water advected up the shelf to reach the divergence zone. Mean bottom currents over the shelf and in particular the across-isobath component (Figure 2a) essentially mirror the surface divergence with dominant upshelf transport taking place 

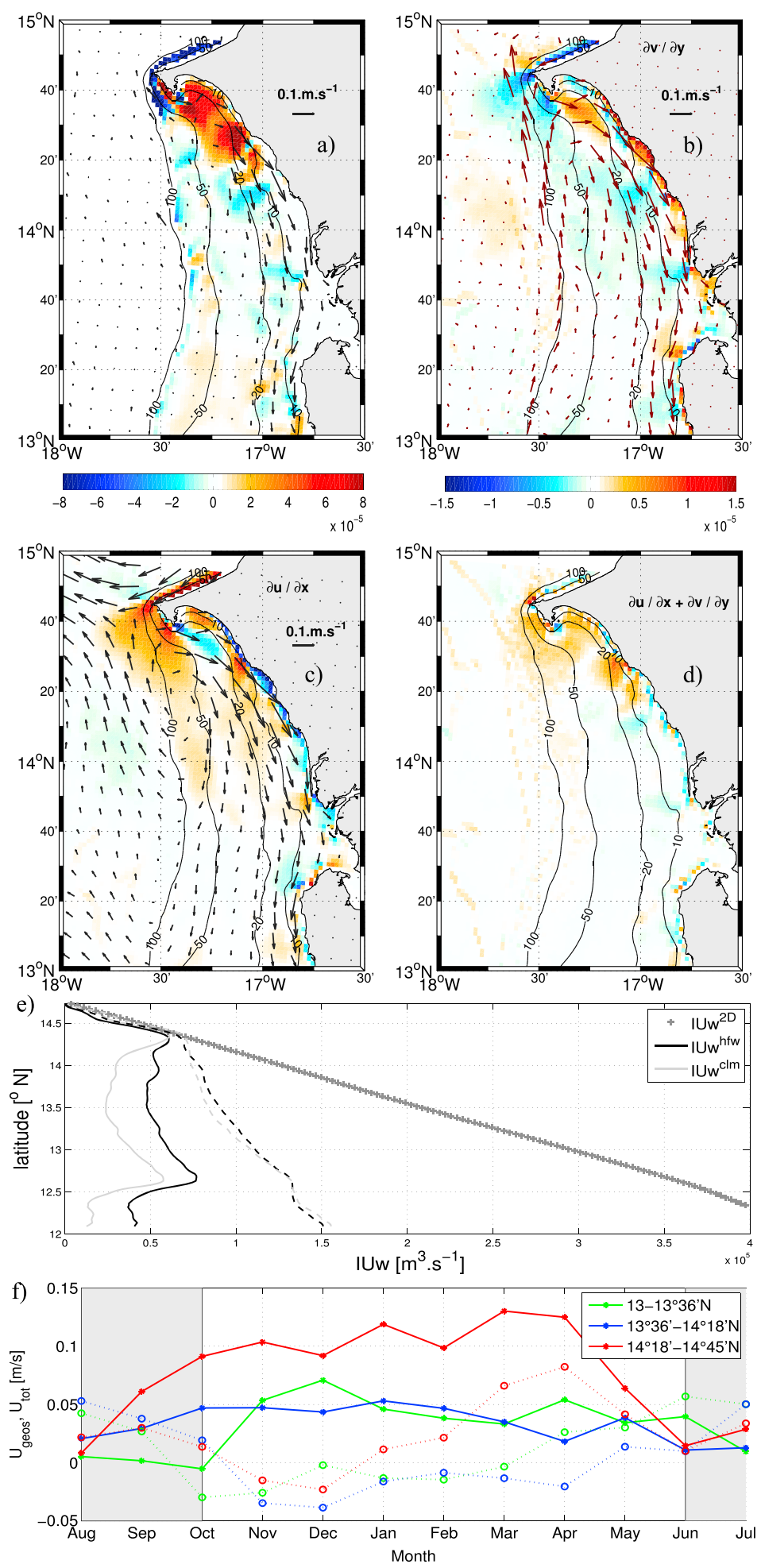

Figure 2. (a) Horizontal bottom currents (vectors) and their associated vertical component $-\boldsymbol{u} \cdot \boldsymbol{\nabla} h$. (b-d) Horizontal flow divergence and its decomposition in the meridional and zonal directions. Middepth (depth-averaged mixed layer) current vectors are superimposed in Figure $2 \mathrm{~b}$ (Figure $2 \mathrm{c}$ ). (e) Net cumulative upwelling $I \mathrm{U}_{w}\left(10^{5} \mathrm{~m}^{3} \mathrm{~s}^{-1}\right)$ computed from model simulations and theory in the SSUS, as a function of latitude of the domain southern limit. Similar estimates neglecting localized downwelling in (1) are also shown with dashed lines. (f) Depth-averaged and meridionally averaged mixed layer zonal velocities (dotted) and its geostrophic component (solid). Meridional averaging is carried out over three different latitude ranges and following the $100 \mathrm{~m}$ isobath. Figures $2 \mathrm{a}-2 \mathrm{~d}$ and $2 \mathrm{f}$ are for the simulation with high-frequency winds $\left(S^{\text {hfw }}\right)$. All quantities are climatological averages over the February-April upwelling period. 
in the northern area. (A more modest bottom upshelf flow also takes place south of $13^{\circ} 30^{\prime} \mathrm{N}$ ). Note that bottom currents do not provide a clear view of the supply of upwelling waters in the deeper part of the shelf where the onshore flow is concentrated around middepth and is also profoundly affected by the geomorphology of the sector (see Figure $2 b$ ).

\subsection{Upwelling Reduction by Onshore Geostrophic Flow}

Ekman dynamics can be strongly disrupted over the shallower parts of the SSUS, e.g., through the coalescence of the surface and bottom Ekman layers [Estrade et al., 2008; Kämpf, 2015]. As for other upwelling sectors it has nonetheless been assumed that, because classical upwelling dynamics is recovered in water depths 30-40 m or even less [Capet et al., 2017], Bakun upwelling indices still provide an accurate quantification of upwelling intensity. This turns out not to be the case in our simulations. Overall, there is considerably less upwelling over the southern Senegal shelf than predicted by Ekman theory and wind forcings. To show this, we compute the net cumulative vertical transport $I_{w}(y)$ across the mixed layer base $\left(a t z=h_{b l}\right.$ ) over the entire shelf width delineated by the $100 \mathrm{~m}$ isobath and coastline (whose positions are denoted $x_{100}(y)$ and $x_{c}(y)$ ), between a latitude $y$ and the northern end of the SSUS at $y_{N}=14^{\circ} 45^{\prime} \mathrm{N}$. Using the fact that $w$ approximately vanishes at the air-sea interface and the continuity equation, we have

$$
w_{\mathrm{hbl}}=-\int_{\mathrm{hbl}}^{0} \partial_{z} w \mathrm{~d} z=\int_{\mathrm{hbl}}^{0}\left(\partial_{x} u+\partial_{y} v\right) \mathrm{d} z
$$

so that

$$
\mathrm{IU}_{w}(y)=\int_{y}^{y_{N}} \int_{x_{100}}^{x_{c}} w_{\mathrm{hbl}} \mathrm{d} x \mathrm{~d} y=\int_{y}^{y_{N}} \int_{x_{100}}^{x_{c}} \int_{\mathrm{hbl}}^{0}\left(\partial_{x} u+\partial_{y} v\right) \mathrm{d} z \mathrm{~d} x \mathrm{~d} y
$$

The integrand in the final form of $\mathrm{IU}_{w}$ is the field shown in Figure $2 \mathrm{~d}$ (whose patterns indicate that choosing $x_{100}$ as offshore integration limit allows us to capture the overwhelming part of the upwelling signal). A useful comparison is with the theoretical vertical transport $I U_{w}^{(2 D)}(y)$ for the quasi-2-D Ekman problem when $\partial_{y} v \equiv 0$ and only Ekman driven flow is present so that

$$
\mathrm{IU}_{w}^{(2 \mathrm{D})}(y)=-\int_{y}^{y_{N}} \int_{\mathrm{hbl}}^{0} u_{\mathrm{ek}}\left(x_{100}\right) \mathrm{d} y=-\frac{1}{\rho_{0} f} \int_{y}^{y_{N}} \tau_{y}\left(x_{100}\right) \mathrm{d} y
$$

where $\tau_{y}\left(x_{100}\right)$ is the wind stress in the meridional direction, which is quasi-parallel to the $100 \mathrm{~m}$ isobath. Model and theoretical vertical transport over the shelf are shown in Figure 2e. In the northernmost 10-20 km $I U_{w}$ and $I U_{w}^{(2 D)}$ are comparable in magnitude. Further south, $I U_{w}$ is relatively constant, whereas $I U_{w}^{(2 D)}$ increases southward at a nearly constant rate (because the wind does not appreciably change over the area). Over the shelf area north of the Senegal-Gambia border $\left(13^{\circ} 35^{\prime} 35^{\prime \prime} \mathrm{N}\right)$, vertical upwelling transport into the mixed layer is only a small fraction of the theoretical transport predicted by Ekman theory (one sixth to one tenth depending on model forcings). Discounting downwelling in (1) (i.e., only summing positive values of horizontal flow divergence) provides a more conservative upper bound for upwelling intensity which is still only $\sim 30 \%$ of the theoretical Ekman-based estimation in $S^{\mathrm{clm}}$ and $S^{\mathrm{hfw}}$. Overall, model enrichment through upwelling and also shelf export/losses to the open ocean $\left(U\left(x_{100}\right)\right)$ are thus strongly decoupled from the 2DV Ekman transport $\left(\mathrm{IU}_{w}^{(2 \mathrm{D})}\right)$.

Coastal upwelling is known to be modulated by the large and mesoscale geostrophic flow [Colas et al., 2008; Marchesiello and Estrade, 2010]. Near cancellation of upwelling south of $14^{\circ} 20^{\prime} \mathrm{N}$ is related to meridional buoyancy and SSH gradients (warmer and higher elevation in the south) that translate into onshore geostrophic flow. This is readily visible in Figures $1 \mathrm{e}-1 \mathrm{f}$ and precisely quantified along the $100 \mathrm{~m}$ isobath in the model (Figure 2f). During the upwelling season the geostrophic flow is onshore with velocity $3-5 \mathrm{~cm}^{-1}\left(\sim 10 \mathrm{~cm}^{-1}\right)$ south (north) of $14^{\circ} 20^{\prime} \mathrm{N}$. This yields a total flow that is onshore in the north (as previously noted) and a major reduction of the offshore flow in the south. Transmission of alongshore pressure gradient signals across a continental shelf is a complex subject [Csanady, 1978; Kelly and Chapman, 1988], but our analysis done at the shelf break captures geostrophic velocities that are also present over shallower parts of the shelf (see Figures 1e-1f). Although geostrophic velocities are formally divergent free on an $f$ plane (i.e., they would have no contribution when inserted into equation (1)), the onshore geostrophic flow modified by lateral friction (and possibly nonlinearities) over the shelf turns out to have a strong impact on SSUS-averaged vertical velocities, in agreement with the idealized studies in Marchesiello and Estrade [2010]. The similarity between observed/simulated SSH patterns and the limited sensitivity of the onshore flow (and $\left.I U_{w}\right)$ to forcing complexity give confidence in the realism of the model dynamics. Nonetheless, the precise figures obtained for 

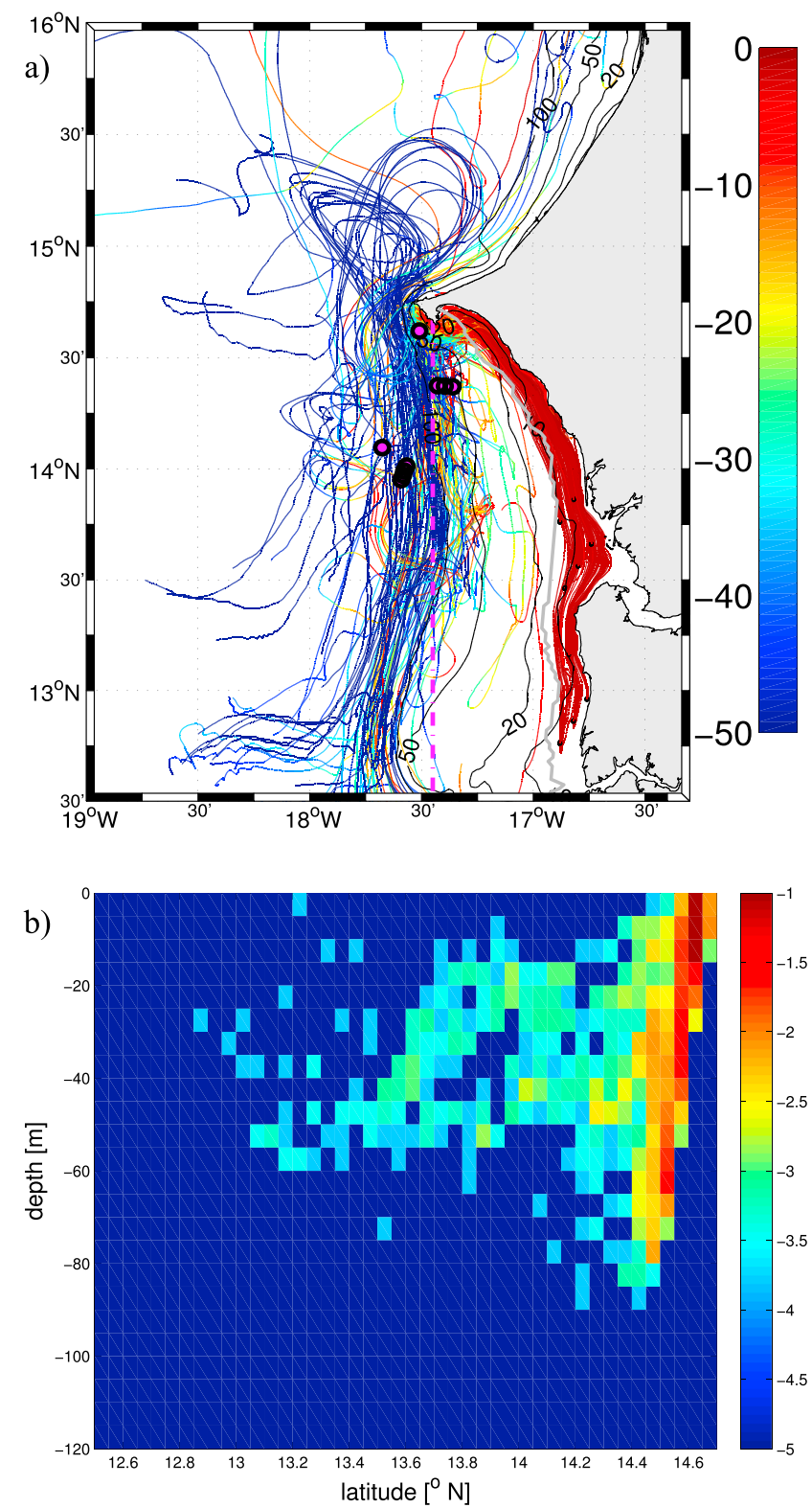

Figure 3. (a) The 150 randomly chosen particle trajectories showing the typical pathways followed by waters to reach the warm inner shelf region. Color coding is for particle depth $(\mathrm{m})$. The magenta line at $17^{\circ} 27^{\prime} \mathrm{N}$ represents the position of the section where particles are intercepted to determine their location of entry onto the shelf. The grey solid line closely following the coast delineates the portion of the shelf where temperature is reconstructed based on a simplified advection plus forcing model (see section 3.4 and supporting information Text S4). Circles in magenta represent the exploration and appraisal wells offshore of the SSUC (adapted from the CAIRN Senegal report for 2016, available at http://www.cairnenergy.com/index.asp?pageid=856. (b) Latitude-depth probability density function for the location of final entry onto the shelf (determined using all trajectories of particles that exit the shelf during their 2 month backward integration; $\log _{10}$ units).

the overall SSUS upwelling intensity presumably depend on imperfect basin-scale open boundary information and how it propagates in our model. A slight excess of alongshore pressure gradient forces would result in a deficit of upwelling compatible with the model SST bias discussed in section 3.1 (but note again the good model/data agreement in regional sea level; see Figure 1).

\subsection{Inner Shelf Circulation and Thermal Structure}

We now focus on the strip of warm water located inshore of the cold upwelling tongue. Existence of that strip is classically understood, in a 2-D vertical subinertial framework, as the consequence of Ekman transport 
shuts down in shallow waters [Estrade et al., 2008]. Essential to this conceptual view is the assumption that momentum is sufficiently well mixed over the inner shelf so that wind and bottom friction equilibrate without involving the Coriolis force. This 2DV explanation leaves key questions unanswered about origin and renewal of the water in the strip. Another issue is that the water column in the strip was observed to be stratified even when upwelling conditions were established, so the 2DV explanation cannot always hold [Capet et al., 2017].

To gain insight into the inner shelf dynamics, we use an offline Lagrangian model and integrate backward in time 12,000 particles released in the warm strip (see details in supporting information Text S3). Trajectories reveal the pathways followed by the particles (Figure 3a). Most drifters ending up in the warm strip originate offshore in the subsurface and are brought to the SSUS by excursions of the northward flowing slope undercurrent (over a broad latitude range but in larger numbers around $13^{\circ} 30^{\prime} \mathrm{N}$ and north of $14^{\circ} \mathrm{N}$, in agreement with mean interior currents shown in Figure $2 b$ ); they are subsequently advected northward and upshelf until they penetrate into the bay situated south of Dakar (locally known as Hann Bight) (80\% of drifters reach to within $15 \mathrm{~km}$ of the northern extremity of the SSUS at $\left.14^{\circ} 45^{\prime} \mathrm{N}\right)$; then, they flow southward while remaining confined nearshore. SSUS inner shelf waters are thus mainly composed of upwelling waters having passed through the Bay of Dakar choke point in the vicinity of which the largest vertical velocities are found (i.e., where most changes in trajectory colors are seen in Figure $3 b$ ).

The simplicity of the Lagrangian trajectories (Figure 3a) and the inner shelf/midshelf currents (Figure 2c) suggests a straightforward explanation for the SSUS nearshore thermal structure: across-shore gradients in heat sinks/sources affecting near-surface waters as they are advected southward approximately uniformly. To test the plausibility of this, we reconstruct the steady state meridional profile of temperature $\bar{T}_{r}^{\text {is }}$ that would result from having inner shelf waters evolve due to net air-sea heat fluxes $\bar{F}_{h}^{\text {is }}(y)$ as they are advected southward by the time- and depth-averaged inner shelf flow $\bar{v}^{\text {is }}$. Neglecting lateral advective and diffusive heat transfers with the rest of the shelf, we thus have (see supporting information Text S4 for details)

$$
\partial_{y} \bar{T}_{(r)}^{\text {is }}(y)=\bar{F}_{h}^{\text {is }} /\left(\rho_{0} c_{p} \bar{H}^{\text {is }} \bar{v}^{\text {is }}\right)
$$

Good correspondence between observed, simulated, and reconstructed coastal temperatures is found (Figure S2), thereby confirming that warm inner shelf temperatures south of $\sim 14^{\circ} 20^{\prime} \mathrm{N}$ can be produced by applying air-sea heat fluxes to recently upwelled waters travelling straight south from northern SSUS, without complex recirculations. In deeper parts of the shelf, southward advection (Figure 2c) and net air-sea fluxes (not shown) are comparable in magnitude but the water column is generally more stratified. Thus, surface cooling by mixing with subsurface waters cannot be neglected. This yields across-shore differences in warming rates of southward flowing surface waters that are qualitatively consistent with the SSUS nearshore temperature pattern. Note, though, that the model has limited horizontal resolution $(\Delta x \approx 2 \mathrm{~km})$ so turbulence at scale $0(1) \mathrm{km}$ and less is not explicitly represented; the possible underestimation of lateral exchanges/mixing in our simulations due to absence of some inner shelf processes such as wave-induced circulation; and large uncertainties in the air-sea heat fluxes. Irrespective of these caveats, our results underscore the 3-D nature of the SSUS dynamics and more specifically the importance of mean alongshore currents in the functioning of the inner shelf, e.g., in terms of retention and enrichment.

\section{Conclusions}

The dynamics of the southern Senegal upwelling sector is investigated by means of ROMS numerical simulations that resolve the frontal features present over the continental shelf during the upwelling season. The presence of Cape Verde exerts a major influence over the mesoscale activity, Ekman coastal divergence, and upwelling circulation (pathways followed by cold subsurface water feeding the coastal divergence and fate of upwelled waters). Existence of significant north to south buoyancy and sea level gradients in the southern fringes of the Canary system also have important implications for the SSUS dynamics. Specifically, our analyses show that (1) the overwhelming fraction of SSUS upwelling takes place in its northern part, within $30 \mathrm{~km}$ from Cape Verde and largely arises from alongshore flow acceleration in the lee of Cape Verde; (2) overall SSUS upwelling intensity is only a small fraction of the upwelling expected from simple Ekman transport theory because the geostrophic flow is robustly onshore and counteracts offshore Ekman drift; and (3) as a consequence of (1) and (2), cross-shore exchanges are strongly diminished in the SSUS which leads to the development of a persistent thermal front reflecting the contrasted evolution of inner shelf and midshelf waters subjected to air-sea heating. 
Interruption of the alongshore flow by the Cape Verde peninsula and shelf widening present immediately to the south are instrumental with respect to conclusion (1). Both conspire to concentrate entries of water onto the midshelf to the north of $14^{\circ} 20^{\prime} \mathrm{N}$, on average. This is in contrast with the diversity of upwelling routes found along the Oregon coast [Rivas and Samelson, 2011]. Convergent onshore currents associated with a recurrent anticyclonic eddy help satisfy the 3-D flow nondivergence in the vicinity of Cape Verde.

Concerning (2), note that more water is presumably drawn onto the shelf than required to close the Ekman circulation, e.g., due to wind synoptic variability or other sources of across-shore intermittent flow such as coastal-trapped waves and slope mesoscale activity [Capet et al., 2017]. Part of this water may be incorporated into the mixed layer through processes unrelated to Ekman transport divergence (e.g., mixing due to superinertial motions) [Avicola et al., 2007; Capet et al., 2017]. Overall enrichment may thus be more intense than our present analyses indicate. Still in the context of (2), the importance of alongshore pressure gradients is qualitatively supported by sea level model-data comparison but a more quantitative investigation is needed. Given uncertainties in sea level estimates, additional model experiments forced at large-scale by various ocean reanalyses would inform of SSUS upwelling rate sensitivities. It seems also quite important to put SSUS primary productivity estimates in perspective with accurate upwelling rates accounting for onshore geostrophic flow contributions [i.e., not solely based on traditional wind-based upwelling indices; Bakun, 1973].

The southern Senegal marine ecosystem plays an outstanding social, economical, and cultural role. A major depollution program has recently started around Dakar that will necessitate several outfalls to be built to release wastewaters within approximately a mile or less from shore [Lewis, 2016]. Oil exploitation in West African waters is moving forward in several locations, including just offshore of the southern Senegal continental shelf (see locations of existing exploration and appraisal wells in Figure 3). In both contexts, a frequent assumption is that upwelling dynamics shall ensure rapid offshore dispersal of near-surface pollutants. This view is seriously challenged by our work which pleads for cautious impact assessments. Onshore transport and nearshore retention of surface waters is pervasive in the northern SSUC which, as our study highlights, plays a major ecological role for small pelagic fish reproduction. Spawning there offers good odds for eggs and larvae of being retained over the shelf into upwelling waters. Circumstantial evidence that the northern SSUS is indeed a favored spawning zone was provided by egg counts performed during the AWA 2014 field experiment. An overwhelming fraction of all fish eggs sampled in the SSUC was found in a limited region north of $14^{\circ} 20^{\prime} \mathrm{N}$ and inshore of the $50 \mathrm{~m}$ isobath (see supporting information Text S5). For Engraulis Encrasicolis no eggs were found outside this sector. All these point to the importance of ensuring a good ecological health status in this zone.

Acknowledgments

We are grateful to the captain and crew of R/V Thalassa for their dedicated support during the AWA 2014 field experiment (DOI 10.17600/14001400). We acknowledge financial support from the IRD through the AWA (grant 01DG12073E) and LMI ECLAIRS programs, from LEFE-INSU FUSE, and from European Union FP7 PREFACE (grant 603521). S.N. was supported by the Programme Doctoral International Modelisation des Systemes Complexes UPMC/IRD. L2 MODIS SST was produced and distributed by NASA Goddard Space Flight Center, Ocean Ecology Laboratory, Ocean Biology Processing Group (http://oceancolor.gsfc.nasa. gov/cms/). The SSALTO/DUACS altimeter products were produced and distributed by the Copernicus Marine and Environment Monitoring Service (CMEMS). MDT CNES-CLS13 was produced by CLS Space Oceanography Division and distributed by AVISO, with support from CNES (http://www.aviso. altimetry.fr/).
Our study has focused on climatological patterns, but the role of synoptic variability will need careful investigation, e.g., with respect to small pelagic fish recruitment success. Inspection of thousands of SST MODIS scenes [Ndoye et al., 2014] suggests that synoptic misfortunes in the form of rapid offshore export must be rare for eggs spawned in the northern SSUC. One such misfortune may have occurred during AWA 2014 when unusual offshore extension of the cold SSUS tongue was observed (Figure S3b), in relation with a sustained period of above-average upwelling wind intensity, and also reduced heat flux from the atmosphere. In this context, modification in the frequency of occurrence of SSUS synoptic states might be a key local expression of climate change in this sector. Changes of the regional-scale thermohaline structure affecting pressure gradients offshore of the SSUS might be another one. This effect is explored in Oerder et al. [2015] for the Humboldt system and turns out to be modest (in comparison to expected changes in wind intensity). A similar investigation is underway for the southern Canary system where the role of longshore pressure gradients appears far more crucial. Conversely, the study of upwelling dynamics in sectors characterized by a wide continental shelf (such as the Sahara Bank and St. Helena Bay in the Benguela system) will benefit from using the type of approach and analyses developed herein.

\section{References}

Avicola, G., J. N. Moum, A. Perlin, and M. D. Levine (2007), Enhanced turbulence due to the superposition of internal gravity waves and a coastal upwelling jet, J. Geophys. Res., 112, C06024, doi:10.1029/2006JC003831.

Bakun, A. (1973), Coastal upwelling indices, west coast of north america, 1946-71, Tech. Rep. NMFS SSRF-671 114, NOAA.

Bakun, A. (1996), Patterns in the Ocean: Ocean Processes and Marine Population Dynamics, California Sea Grant, on cooperation with Centro de Investigaciones Biologicas del Noroeste, La Paz, Mexico.

Barnier, B., L. Siefried, and P. Marchesiello (1995), Thermal forcing for a global ocean circulation model using a three-year climatology of ECMWF analyses, J. Mar. Syst., 6, 363-380. 
Barth, J. A., S. Pierce, and R. Castelao (2005), Time-dependent, wind-driven flow over a shallow midshelf submarine bank, J. Geophys. Res., 110, C10S05, doi:10.1029/2004JC002761.

Bentamy, A., and D. C. Fillon (2012), Gridded surface wind fields from Metop/ASCAT measurements, Int. J. Remote Sens., 33, 1729-1754.

Brink, K., B. Jones, J. Van Leer, C. Mooers, D. Stuart, M. Stevenson, R. Dugdale, and G. Heburn (1981), Physical and biological structure and variability in an upwelling center off Peru near 15 s during March, 1977, in Coastal Upwelling, pp. 473-495, AGU, Washington, D. C., doi:10.1029/CO001 p0473.

Capet, X., P. Estrade, E. Machu, S. Ndoye, J. Grelet, A. Lazar, L. Mari, D. Dausse, and P. Brehmer (2017), On the dynamics of the southern Senegal upwelling center: Observed variability from synoptic to superinertial scales, J. Phys. Oceanogr., 47(1), 155-180, doi:10.1175/JPO-D-15-0247.1.

Capet, X. J., P. Marchesiello, and J. C. McWilliams (2004), Upwelling response to coastal wind profiles, Geophys. Res. Lett., 31, L13311, doi:10.1029/2004GL020123.

Carton, J., and B. Giese (2008), A reanalysis of ocean climate using Simple Ocean Data Assimilation (SODA), Mon. Weather Rev., 136, 2999-3017.

Colas, F., X. Capet, J. C. McWilliams, and A. Shchepetkin (2008), 1997-98 El Nino off Peru: A numerical study, Prog. Oceanog., 79, 138-155. Csanady, G. (1978), The arrested topographic wave, J. Phys. Oceanogr., 8, 47-62.

Debreu, L., and E. Blayo (2008), Two-way embedding algorithms: A review, Ocean Dyn., 58, 415-428.

Demarcq, H., and V. Faure (2000), Coastal upwelling and associated retention indices derived from satellite SST. Application to octopus vulgaris recruitment, Oceanolo. Acta, 23, 391-408.

Ekman, V. W. (1905), On the influence of the Earth's rotation on ocean currents, Ark. Mat. Astron. Fys., 2, 1-53.

Estrade, P., P. Marchesiello, and A. Colin (2008), Cross-shelf structure of coastal upwelling: A two-dimensional extension of Ekman's theory and a mechanism for inner shelf upwelling shut down, J. Mar. Res., 66(5), 589-616.

Gan, J., A. Cheung, X. Guo, and L. Li (2009), Intensified upwelling over a widened shelf in the northeastern South China Sea, J. Geophys. Res., 114, C09019, doi:10.1029/2007JC004660.

Graham, W. M., and J. L. Largier (1997), Upwelling shadows as nearshore retention sites: The example of northern Monterey Bay, Cont. Shelf Res., $17,509-532$.

Jones, B. H., K. H. Brink, R. C. Dugdale, D. W. Stuart, J. C. Van Leer, D. Blasco, and J. C. Kelley (1983), Observations of a persistent upwelling center off Point Conception, California, in Coastal Upwelling Its Sediment Record, pp. 37-60, Springer, Plenum Press, Boston.

Kämpf, J. (2015), Interference of wind-driven and pressure gradient-driven flows in shallow homogeneous water bodies, Ocean Dyn., 65(11), 1399-1410, doi:10.1007/s10236-015-0882-2.

Kelly, K. A., and D. C. Chapman (1988), The response of stratified shelf and slope waters to steady offshore forcing, J. Phys. Oceanogr., 18, 906-925.

Large, W., J. McWilliams, and S. Doney (1994), Oceanic vertical mixing: A review and a model with a nonlocal boundary layer parameterization, Rev. Geophys., 32, 363-403.

Lewis, J. (2016), Cleaning up muddy waters: The fight to revive Senegal's Hann Bay, Environ. Health Perspect., 124(5), A92-A97.

Marchesiello, P., and P. Estrade (2010), Upwelling limitation by onshore geostrophic flow, J. Mar. Res., 68, 37-62.

Ndoye, S., X. Capet, P. Estrade, B. Sow, D. Dagorne, A. Lazar, A. Gaye, and P. Brehmer (2014), SST patterns and dynamics of the southern Senegal-Gambia upwelling center, J. Geophys. Res. Oceans, 119, 8315-8335, doi:10.1002/2014JC010242.

Oerder, V., F. Colas, V. Echevin, F. Codron, J. Tam, and A. Belmadani (2015), Peru-Chile upwelling dynamics under climate change, J. Geophys. Res. Oceans, 120, 1152-1172, doi:10.1002/2014JC010299.

Praveen Kumar, B., J. Vialard, M. Lengaigne, V. Murty, M. McPhaden, M. Cronin, F. Pinsard, and K. Gopala Reddy (2013), Tropflux wind stresses over the tropical oceans: Evaluation and comparison with other products, Clim. Dyn., 40(7-8), 2049-2071, doi:10.1007/s00382-012-1455-4.

Pringle, J. M. (2002), Enhancement of wind-driven upwelling and downwelling by alongshore bathymetric variability*, J. Phys. Oceanogr., $32,3101-3112$.

Ramp, S. R., J. D. Paduan, I. Shulman, J. Kindle, F. L. Bahr, and F. Chavez (2005), Observations of upwelling and relaxation events in the northern Monterey Bay during August 2000, J. Geophys. Res., 110, C07013, doi:10.1029/2004JC002538.

Rebert, J.-P., and M. Privé (1974), Observations de courant sur le plateau continental sénégalais du cap Vert au cap Roxo: Campagne 74.10, Mars 1974, Archive - CRODT, 20 p., ORSTOM; CRODT.

Rio, M., S. Guinehut, and G. Larnicol (2011), New CNES-CLS09 global mean dynamic topography computed from the combination of GRACE data, altimetry, and in situ measurements, J. Geophys. Res., 116, C07018, doi:10.1029/2010JC006505.

Risien, C. M., and D. B. Chelton (2008), A global climatology of surface wind and wind stress fields from eight years of QuikSCAT scatterometer data, J. Phys. Oceanogr., 38, 2379-2413.

Rivas, D., and R. M. Samelson (2011), A numerical modeling study of the upwelling source waters along the oregon coast during 2005, J. Phys. Oceanogr., 41(1), 88-112, doi:10.1175/2010JPO4327.1.

Rosenfeld, L. K., F. B. Schwing, N. Garfield, and D. E. Tracy (1994), Bifurcated flow from an upwelling center: A cold water source for Monterey Bay, Cont. Shelf Res., 14, 931-964.

Roughan, M., A. J. Mace, J. L. Largier, S. G. Morgan, J. L. Fisher, and M. L. Carter (2005), Subsurface recirculation and larval retention in the lee of a small headland: A variation on the upwelling shadow theme, J. Geophys. Res., 110, C10027, doi:10.1029/2005JC002898.

Shchepetkin, A., and J. C. McWilliams (2005), The Regional Oceanic Modeling System: A split-explicit, free-surface, topography-following-coordinate ocean model, Ocean Model., 9, 347-404.

Shchepetkin, A., and J. C. McWilliams (2009), Correction and commentary for "Ocean forecasting in terrain-following coordinates: Formulation and skill assessment of the regional ocean modeling system" by Haidvogel et al., J. Comp. Phys. 227, pp. 3595-3624, J. Comput. Phys., 228, 8985-9000.

Worley, S. J., S. Woodruff, R. Reynolds, S. Lubker, and N. Lott (2005), ICOADS release 2.1 data and products, Int. J. Climatol., 25, 823-842.

Yokomizo, H., L. W. Botsford, M. D. Holland, C. A. Lawrence, and A. Hastings (2010), Optimal wind patterns for biological production in shelf ecosystems driven by coastal upwelling, Theor. Ecol., 3(1), 53-63, doi:10.1007/s12080-009-0053-5.

Zhang, Y., J. G. Bellingham, J. P. Ryan, and M. A. Godin (2015), Evolution of a physical and biological front from upwelling to relaxation, Cont. Shelf Res., 108, 55-64. 